\section{The Usefulness of Operating Cash Flow for Predicting Business Bankruptcy in Medium-Sized Firms}

\author{
Natividad Rodríguez-Masero ${ }^{1}$ \\ Jesús D. López-Manjón ${ }^{1}$ \\ ${ }^{1}$ Pablo de Olavide University, Financial Economics and Accounting, Seville, Spain
}

\begin{abstract}
Purpose - This paper proposes using operating cash flow (OCF) as an instrument to determine a firm's likelihood of bankruptcy. It presents a new model capable of predicting business failure based on data derived from financial statements.
\end{abstract}

Design/methodology/approach - In this study, logit analysis was employed because of its frequently-cited conceptual advantages relative to multiple discriminant analysis. Through the logistic regression, we identified an integrated function for several ratios, which is useful when assessing whether a firm can be classified as solvent or insolvent in the future. The sample consists of Spanish medium-sized enterprises (MEs) included in the SABI.

Findings - We identified an integrated function for several ratios, including information derived from cash flow statements, which is useful when assessing whether a firm can be classified as solvent or insolvent in the future. The analysis suggests the usefulness of taking into account information provided by cash flow statements when making decisions regarding lending to firms and, also, in relation to the acceptable level of leverage that can be assumed by a firm.

Originality/value - The model is capable of predicting the probability that a medium-sized firm might have financial problems three years before this occurs, increasing the capacity to take corrective measures.

Keywords - business failure prediction, operating cash flow, Spanish mediumsized firms, accounting ratios.
Received on:

05/30/2019

Approved on:

$04 / 29 / 2020$

Responsible Editor:

Prof. Dr. Ilídio Lopes

\section{Evaluation process:}

Double Blind Review

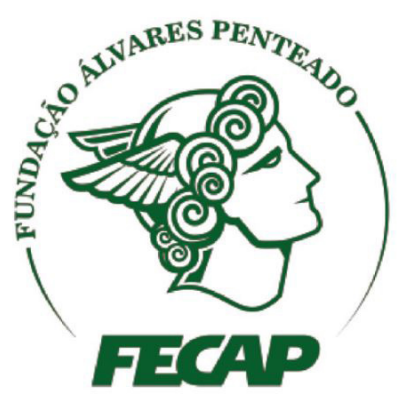

Revista Brasileira de Gestáo de Negócios

https://doi.org/10.7819/rbgn.v22i4.4079 


\section{Introduction}

This paper examines a model based on accounting information derived from financial statements and that is mainly focused on one variable, operating cash flow (OCF), which is not frequently used in these studies. Furthermore, the study seeks to contribute to the literature on predicting failure in medium-sized firms. As Tascón, Castańo and Castro (2018) pointed out, although recent studies generally recognise that SMEs require specific tools for risk management in accordance with their particular characteristics, these kinds of businesses have received less attention than large and/or listed firms. The current accounting regulations in Spain require medium-sized firms to provide such information in their cash flow statement. However, cash flow statements are not compulsory for small firms; therefore, small businesses have not been included in the sample.

The obtained model achieves its highest success rate, of $95.24 \%$ accurate classifications, at three years, which is a high success rate compared to previous models and provides longer notice until the time of failure. According to the review carried out by Jardin (2015), the accuracy of traditional models decreases beyond one year. According to the same review, the model with the highest accuracy at three years (Gepp \& Kumar, 2008) achieved $90.5 \%$ correct classifications and a year in advance only three models exceeded 95\% (Gepp \& Kumar, 2008; Korol, 2013; Sun, Jia, \& Li, 2011). According to Jardin (2015), the accuracy of this estimation over a mid-term horizon is relevant to value the risk of financial institutions, which exists until the maturity of their loans. Moreover, from the perspective of the debtor firm, the possibility of foreseeing business failure with a margin of three years increases the capacity to take measures to correct the situation before it happens.

As the literature (Mari-Vidal, Marin-Sánchez, Seguí-Mas, \& Michael-Zamorano, 2014; Tascón \& Castaño, 2012) has pointed out, there is no commonly accepted framework regarding business failure or its determining factors, and most of the research is geared toward testing the informative content of financial statements as a predictor, looking for a relationship between accounting data and future solvency. The use of non-accounting data in these models has been scarce, even though, according to Tascón and Castaño (2012), the results tend to improve when some of these non-financial variables are included. Authors such as Campillo, Serer, and Ferrer (2013) have shown that the accounting information provided by firms is useful when conducting this kind of research, yielding consistent results. In the same line, Altman, Iwanicz \Drozdowska, Laitinen, and Suvas (2017) cite several recent reviews of the efficacy of these models that conclude that the difference in the predictive accuracy of accounting-based and market-based models is not significant; however, the use of accounting-based models allows for a higher level of risk-adjusted return on credit activity (Agarwal \& Taffler, 2008).

Finally, as Serer, Campillo, and Feres, (2009) pointed out, the timeframe must be considered a key variable in business failure predictions. Taking this idea into account, the present study follows the proposal made by Pina (1998) and cited by Enguídanos (2009), which involves using values of ratios calculated for several years prior to failure.

The rest of the paper is as follows. A literature review on business failure prediction is presented in section 2. Section 3 describes the data and methodological aspects, including a description of the sample, the definition of variables, and the methodology employed in the empirical research. Next, section 4 sets out the results obtained, and finally, section 5 presents the main conclusions of the research.

\section{Background}

\section{I The concept of failure}

First of all, it is important to clarify what we understand by failure in this paper, since there are different definitions for this concept in the literature. As indicated by Mari-Vidal et al. (2014), we can basically group these definitions into two blocks: those that opt for an economic approach and those that apply a legal approach. The economic perspective gives rise to a wide variety of options. Tascón and Castaño (2012) cite Graveline and Kokalari (2008), who mention three groups of concepts: ceasing to repay a debt; meeting the conditions set forth in current bankruptcy regulations; or having a patrimonial situation that is a precursor to future failure. One representative of this third option is Altman (1981), who defines failure as technical insolvency or in the sense of capital with a lack of liquidity. In turn, another group of authors (Gilbert, Menon, \& Schwartx, 1990; Hill, Perry, $\&$ Andes, 1996) refers to the prolongation of continued losses. Gazengel and Thomas (1992) consider a failed 
firm to be one that cyclically generates more financial burden than income. And more recently, Davydenko (2007) argues that when the equity situation reflects a reduced value in assets or a shortage of cash, this can trigger business failure. Misas (2008) and Rodriguéz, Molina, and Pérez (2003) consider an entity to be unsuccessful when it incurs technical bankruptcy, understanding this to mean negative net equity (Tascón \& Castaño, 2012).

The fact that in the legal approach an objective criterion can be used to classify firms between failed and unsuccessful has been decisive in its greater use, as indicated by Mari-Vidal et al. (2014) and Somoza-López and Vallverdu-Calafell (2003). It has used done in the case of Spain, for example, by Campillo et al. (2013) and García-Marí, Sánchez-Vidal, and Tomaseti-Solano (2016). The first authors defended the option, indicating that its drawbacks (basically the considerable reduction of sample sizes) were overcome "by the advantages of objectivity and setting the date of failure in the selection process" (Campillo et al., 2013, p. 31). Consequently, this work understands failure to refer to a firm's initiation of legal insolvency proceedings, or "concurso de acreedores" in the Spanish legislation, and establishes the date of failure to be the moment the judge issues a ruling in this regard.

\subsection{Financial ratios and bankruptcy prediction}

The main line of research into business failure has so far focused on estimating a reliable prediction model, aiming to build a useful tool to prevent and correct business failure before it occurs (García-Marí et al., 2016). Most of the research aims to test the informative content of financial statements as a predictive element, seeking a relationship between accounting data and future solvency (Mari-Vidal et al., 2014).

As mentioned, the literature cites Beaver (1966) as a pioneering author in studying the usefulness of accounting information to predict business failure, although his main objective was not to predict business failure, but rather to show the informative potential of accounting data. His contributions represented a great qualitative leap in the research, incorporating univariate discriminant analysis and evaluating the predictive capacity of the ratios separately. Subsequently, Altman (1968) included multivariate analysis, being the first to apply this technique to predict business failure.
These models were followed, with notable improvements, by those proposed by Altman, Haldeman and Narayanan (1977), Deakin (1972), Edmister (1972), Sinkey (1975), and Taffler (1983). This body of research achieved good results with small classification errors, although the statistical restrictions to which this methodology is subject (independence and normality of the variables and equality of the variance-covariance matrices) greatly distorted the results, lowering their degree of reliability (Campillo et al., 2013). Later works have used logistic regressions with logit or probit models (Martin, 1977), artificial intelligence techniques (Bell, Ribar, \& Verchio, 1990; Serrano-Cinca, 1996; Shin \& Lee, 2002), or DEA (Paradi, Asmild, \& Simak, 2004). In the case of Spanish firms, a pioneering model was developed by Professor Amat in his doctoral thesis of 1990 and reformulated in 2008, obtaining a score where positive values indicate that the firm has a high probability of enjoying good economicfinancial health. Both for Spanish and international cases, the abovementioned literature reviews by Campillo et al. (2013) and Tascón and Castaño (2012) show an increasing group of techniques that use financial ratios to predict business failure, such as multiple discriminant analysis (MDA), logistic regression (LR), artificial neural network (ANN), support vector machines (SVM), rough sets (RS), case-based reasoning (CBR), decision tree (DT) and genetic algorithm (GA), which are mentioned in the review developed by Alaka et al. (2018). Of all these techniques, Tascón et al. (2018) indicate that the most used techniques for predicting business failure in SMEs are linear discriminant analysis (LDA), quadratic discriminant analysis (QDA), logit and probit. These authors (Tascón et al., 2018) add a remarkable recent innovation, based on the use of differences in percentiles to calculate the distance to failure in a specific group of firms. This work tested its model on a sample of small Spanish firms from the construction industry.

Amat, Manini and Renart (2017) refer to the literature reviews developed by Abdou and Pointon (2011), concluding, among other things, that there is not yet one technique that dominates over the others. So, according to these authors, the traditional statistical techniques are often used rather than techniques such as neural networks, decision trees and genetic programming because the former have been proven to perform very well. The predicting capabilities of both groups of approaches were sufficiently similar to make it difficult to distinguish 
between them (Abdou \& Pointon, 2011), as mentioned by Amat et al. (2017).

\subsection{Use of indicators}

Altman Z scores, considered in one of the seminal works on the use of accounting ratios to predict business failure, use ratios both in the original model and in more recent versions, classifiable into five standard categories: liquidity, profitability, leverage, solvency, and activity. In the same line, the literature review conducted by Tascón and Castaño (2012) shows that profitability, indebtedness and economic-financial balance are the most commonly used indicators in the literature in models for predicting failure (see Table 1).

The most frequently used ratios in that sample are represented in more detail in Table 2.

One of the more recent studies in Spain (Tascón et al., 2018) uses variables such as TL/TA (total liabilities/total assets), CA/CL (current assets/current liabilities), EBIT/ TA (earnings before interests and taxes/total assets), NI/ TA (net income/total assets), CA/TA (current assets/total assets), FE/TL (financial expenses/total liabilities), RP/TA (retained earnings/total assets), CF/TL (cash flow/total liabilities), NI/SL (net income/sales) and SL/TA (sales/ total assets). The work, which studies the construction industry, finds that ratios of cash flow ${ }^{\mathrm{i}}$, return on assets and indebtedness are the most discriminant.

Based on all the above, we propose a model that takes into account the three most frequently used variables in the previous Spanish literature:

a) return on assets, as an indicator of economic profitability measured as operating income/total assets;

b) total liabilities/total assets, as a ratio belonging to the indebtedness category;

c) current assets/current liabilities, as the most representative ratio of eco-financial balance.

Our proposal in this paper is to include operating cash flow (OCF) as the main indicator of a firm's capacity to repay its debts. The use of OCF as an explanatory variable is justified by the following:

a) It takes into account the changes in current capital, thus reaching a cash flow figure based on the difference between collections and payments;
Table 1.

Ratio category

\begin{tabular}{ccc}
\hline Ratio category & Items & Percentage \\
\hline Profitability & 64 & $17.44 \%$ \\
Indebtedness & 55 & $14.99 \%$ \\
Eco-Financial balance & 42 & $11.44 \%$ \\
\hline
\end{tabular}

Table 2.

\section{Most frequently used ratios}

\begin{tabular}{cc}
\hline RATIO & $\begin{array}{c}\text { NUMBER } \\
\text { OF } \\
\text { STUDIES }\end{array}$ \\
\hline Total Liabilities / Total Asset & 18 \\
Current Assets / Current Liabilities & 14 \\
BAIT / Total Asset & 14 \\
Net Profit / Total Assets & 14 \\
Current Assets / Total Assets & 10 \\
Undistributed Benefits / Total Assets & 7 \\
Financial Expenses / Required Liabilities & 7 \\
Resources Generated / Required Liabilities & 7 \\
\hline
\end{tabular}

b) It does not take account of flows not directly related to the main activity of the firm (such as those obtained from the sale of fixed assets) and which would tend to be less recurrent in future periods;

c) As all the indicators are based on flow measures, it provides a dynamic measure of cash management, unlike the static vision offered by ratios based on the data derived from stock measures such as the treasury value registered on the balance sheet;

d) The previous literature has emphasised its usefulness when evaluating the situation of highly indebted firms or for predicting bankruptcy risk, which, in our opinion, makes it particularly useful as a determinant of the financial structure of firms during periods of tougher lending requirements.

Additionally, the Spanish regulations allow us to arrange the data in a time horizon and using a sample with a sufficient number of firms. In short, we agree with Mills and Yamamura (1990) that ratios based on the cash flow statement offer a better measure of liquidity than those included in the balance sheet and income statement.

As for the solvency indicators used, those based on asset guarantees are more common than those based 
on the ability to repay debts, or the financial expenses associated with them, with the resources generated (Mateos, 2008 cited in Marí-Vidal et al., 2014). Since cash generation is key to maintaining a firm's day-to-day operations, we are troubled by the omission of indicators that take into account the cash flow statement. In a similar previous review, Somoza-López and VallverduCalafell (2009) did not include that type of data either, but at the time this could be attributed to the fact that that information was not mandatory for most Spanish firms until the entry into force of the Spanish General Accounting Plan in 2007.

In short, we have included in our model a fourth ratio, which is the main novel contribution of the study:

Operating cash flow/total liabilities. In line with our theoretical considerations, this ratio includes data from the cash flow statement that are used as a measure of a firm's ability to repay debts with liquid resources generated by the firm's main and recurring activity. For this ratio we take the value of the operating cash flow provided by the cash flow statement. Spanish accounting regulations opt for an indirect OCF presentation model, so it is calculated based on the result before taxes and making subsequent adjustments. ${ }^{\text {ii }}$

\subsection{Literature on cash flow statements and failure prediction}

The previous literature on the influence of cash flow statements on the financial structure and/or predicting the insolvency of firms does not offer conclusive results. The work of Casey and Bartczak (1985) states that although some previous articles (Gombola \& Ketz, 1983; Gombola, Haskins, Ketz, \& Williams, 1987) had found that ratios based on OCF could be useful in describing and predicting business structures, their results did not find that relationship for the prediction of bankruptcy. In fact, the introduction of ratios based on cash flow statements did not produce any increase in significance for models based on "accrual" variables. A previous study by the same authors (Casey \& Bartczak, 1984) had already concluded that multivariate discriminant models based on accrual-based ratios predicted corporate bankruptcy more adequately than any simple model based on OCF data. Several years later, Aziz and Lawson (1989) demonstrated that operating cash flow and lender cash flow, among others, are important variables for predicting bankruptcy, making a contribution to conservative lending/investing activities without a significant loss in overall prediction accuracy in comparison with Z models. Mills and Yamamura (1990) encouraged auditors to take into account - as their work was already done by lenders, rating agencies and analysts -cash flow statement data when assessing the solvency of firms, especially the OCF/current liabilities and interest coverage ratios. Laitinen (1994) focused on differentiating between the capacity to predict business failure of cash flow, understood as the sum of benefits plus amortizations and depreciations (the author called it TRCF) ${ }^{\mathrm{iii}}$, and the cash flow taken from cash flow statements (OPCF), finding that the discriminatory power of OPCF fluctuates cyclically year by year, reaching its highest value in the second year before failure. The author attributes these fluctuations to the adjustment behaviour in the sample firms because they do not emerge in the discriminatory power of TRCF. The discriminatory power of TRCF is high in comparison to that of OPCF especially in the first year before failure. However, OPCF outperforms TRCF as a discriminator in the fourth year before failure.

There does seem to be agreement, however, regarding the greater importance of cash flow statement data in cases of firms with high levels of leverage and/or financial difficulties. Beaver (1966), DeFond and Hung (2003), and Ohlson (1980) argue in favour of the importance of cash flow information when assessing the credit risks and predicting the bankruptcy of distressed firms. In turn, Previts, Bricker, Robinson, and Young (1994) found that cash flows seemed to be more important for analysts when evaluating firms that are highly leveraged, and Graham, Harvey, and Rajgopal (2005) report that executives consider cash flow measures to be more important for external agents than benefits in cases in which the firm is close to financial difficulties. Lee (2012) makes reference to the work of Sharma (2001), who finds that cash flows provide incremental information for the correct classification of a sample of firms between failed firms and healthy ones. A more recent study (Bhandari \& Iyer, 2013) proposed a business failure prediction model based on ratios that take data from the cash flow statement instead of the income statement. Its model replaces the variables taken from the income statement with OCF and is able to predict, with a considerable rate of success, the failure of North American firms in a multi-sector sample.

The relatively recent creation of the regulatory obligation for Spanish firms to publish their cash flow statements and, therefore, the difficulty in obtaining 
cash flow data until after 2005 or even 2008, explains the even greater shortage of work in the Spanish field. Diéguez-Soto (2009) states that the figure for cash flows from ordinary activities is the key indicator when assessing technical solvency. The aforementioned study by Tascón et al. (2018) uses a cash flow/total debt ratio, although the authors do not identify the origin of this cash flow data (see footnote 1).

\section{Data and Methodological Aspects}

\section{I Sample}

The sample consists of Spanish medium-sized enterprises (MEs) available in SABI. This database provides economic and financial information from Spanish and Portuguese Central Trade Registers. According to Spanish accounting regulations, only firms with specific size features (assets, income and employees) are obliged to produce a cash flow statement, which is essential to our study. Hence, the sample is restricted to firms that compile the "normal" model of financial statements, which excludes small firms, meaning $97.11 \%$ of the Spanish firms registered in the database in 2017. Furthermore, the cash flow statement is a relatively recent introduction, brought into force by the current Spanish General Accounting Plan, from 2008 onwards, which limits the period for which this statement is available.

We work with the most frequently used sampling method, according to García-Gallego and Mures-Quintana (2013), which consists of selecting the sample of failed firms and then choosing the same number of non-failed firms, matching them with the failed ones according to their sector and size. This kind of sample, which Zmijewski (1984) defines based on a state-based sample, presents the advantage of assuring a sufficiently large number of failed firms in the sample, as there is a low rate of companies that have failed in the economy in general, compared to the non-failed ones. In this case, we used a mixed procedure to select the sample. The final sample consists of 1,964 firms and is divided into the following groups:

a. An initial sample, selected according the aforementioned method, comprising 142 firms;

b. A second group that comprises 1,812 firms.

The initial sample comprised 142 firms, 71 of which failed in 2015 and 2016, and 71 of which belong to the non-failed group from the same period. We included in this group all the failed firms where accounting information was available in the SABI database.

Financial and insurance firms were excluded, along with education and government organisations, because of their particular characteristics. We also excluded firms that do not provide some of the data within the selected time period. Subsequently, we selected another group of non-failed firms in which features of size, age, location and industry had a similar weight as the failed group. The remaining group, used as a control sample, comprises 1,792 non-failed firms at the time the database query was submitted and 30 failed firms in 2011-2014 and 20172018 , found in webconcursaliv. This control sample is used to test our model, and all the firms included fulfil the original requirements regarding accounting information availability.

The main period of the study, 2015-2016, is subsequent to the global financial crisis, thereby seeking to avoid the possible influence of it on our results. The time horizon is constrained by the availability of accounting information.

\subsection{Definition of variables}

As mentioned before, we propose a model that takes into account the three most frequently used variables in the prior Spanish literature according to the review conducted by Tascón and Castaño (2012), and we add a variable aimed at measuring the ability to repay debt. Below we present the definitions and implications of each of these variables.

\section{Dependent variable}

The objective of this study is to determine the probability of firm failure. Therefore, in the dependent variable we estimate this probability under the assumption of a logistic distribution expressed in binary form ( 0 , 1) (Alaka et al., 2018). Consequently, the dependent variable takes the value 1 if the firm is financially healthy and 0 otherwise.

\section{Independent variable}

The explanatory variables, and their expected relationships with the dependant variables, are as follow:

Return on assets: an indicator of performance or economic profitability measured as operating income/ total assets. The ratio considers the returns generated from 
the assets regardless of financing, via equity or liabilities, and the cost thereof. ROA is used in 14 of the studies analysed by Tascón and Castańo (2012). A firm's ability to generate profits must contribute to its financial health and, therefore, the sign given in the formula for this ratio is positive. The higher the profitability, the greater the possibility of the business increasing its equity, therefore reducing the probability of default.

a) Level of indebtedness is a core point for testing the solvency of a firm. It is measured as total liabilities/total assets, so we calculate the percentage of assets financed by external resources or, in other words, financed by resources that the firm has an obligation to repay in the future. It also represents the proportion of external financing in the total financial structure of the firm. It is the most widely used ratio according to the results of Tascón and Castańo (2012), being used in a total of 18 studies. A negative relationship is expected between the company's level of indebtedness and probability of financial health, given that a greater amount of debt in proportion to the company's own funds will make it more likely that the firm will have problems in meeting its payment obligations, so the sign in the regression of this indicator should be negative.

b) The current ratio, used as a liquidity measure, compares the assets that will become cash in the short term with the liabilities that the firm has to repay in that same period. Liquidity problems can be the consequence of a firm's excessive or inadequate overall debt, or be directly caused by inadequate management or poor operating activity performance. In any case, the lack of liquidity to cover short-term payments is a cause for bankruptcy. We use the traditional current ratio, current assets/current liabilities, as the liquidity variable in this study. According to Tascón and Castaño (2012), 10 previous models have included the liquidity ratio. The existence of more cashable assets than payable liabilities in the short term decreases the probability of default for the company, so the sign in the formula for this ratio is positive. The reasoning is similar to that presented for the level of indebtedness, but with the focus on the required obligations, and the available resources, in the short term.

c) The final variable seeks to measure a firm's ability to repay its debts through its normal activity. Traditional solvency ratios compare the value of assets with the amount of liabilities. However, these comparisons do not take into account the rate at which assets become liquid following their expected period of use or the possible differences between book values and liquidation values, focusing on the possibility that creditors will recover their loans and not so much on the ability of the firm to repay whilst maintaining its regular activity. In the words of Mateos (2008, cited by Marí et al., 2014), traditional solvency indicators are not focused enough on the firm's capacity to generate resources in order to cope with the repayment of debts and the associated financial expenses. Therefore, we include the variable operating cash flow/total liabilities to measure this ability to repay. The greater this ability, the lower the risk of bankruptcy, so the expected sign is positive.

Table 3 summarises the expected signs of the explanatory variables.

\subsection{Methodology}

A review of the literature shows a wide range of techniques, with Beaver (1966) being considered the pioneer author in studying the usefulness of accounting information to predict business failure, incorporating univariate discriminant analysis and evaluating the predictive capacity of the ratios separately. Subsequently, Altman

\section{Table 3.}

\section{Explanatory variables}

\begin{tabular}{ccc}
\hline Notation & Explanatory variable & $\begin{array}{c}\text { Expected } \\
\text { relationship }\end{array}$ \\
\hline ROA & Operating Income/Total & + \\
& Assets & \\
$T L / T A$ & Total Liabilities/Total & - \\
& Assets & + \\
CURRENT & Current Assets/Current & + \\
RATIO & Liabilities & + \\
OCF/TL & $\begin{array}{c}\text { Operating Cash Flow/ } \\
\text { Total Liabilities }\end{array}$ \\
\hline
\end{tabular}

Note. The sample is composed of 1,964 Spanish small and medium-sized enterprises (SMEs) for the period 2011-2018. 
(1968) included multivariate analysis, being the first to apply this technique to predict business failure. These models were followed, with notable improvements, by those proposed by Altman et al. (1977), Deakin (1972), Edmister (1972), Sinkey (1975), and Taffler (1983). This body of research achieved good results with small classification errors, although the statistical restrictions to which this methodology is subject (independence and normality of the variables and equality of the variancecovariance matrices) greatly distorted the results, lowering their degree of reliability (Campillo et al., 2013).

Within the conditional probability models, we will use logit analysis. This is the most widely used analysis method for modelling bankruptcy prediction since it does not pose restrictions regarding normality in the distribution of the independent variables or the equality of the variance-covariance matrices. Therefore, logit seems to be more appropriate for this kind of study than discriminant analysis (Lo, 1986). The literature reviews conducted by Alaka et al. (2018), Campillo et al. (2013), Jardin (2015), and Tascón and Castaño (2012) show an increasing group of techniques that use financial ratios to predict business failure. The logit model assumes that the logarithm of the probability ratio is linearly related to the explanatory variables.

Furthermore, logit analysis was employed in this study because of its frequently mentioned conceptual advantages relative to multiple discriminant analysis (Zavgren, 1983). The main reason is that logit analysis assumes the dependent variable is dichotomous. Through the logistic regression, we identified an integrated function for several ratios, which is useful in assessing whether a firm might be classified as solvent or insolvent in the future.

Depending on the value of the formula below, we can determine whether a company is likely to be financially healthy or to have insolvency problems.

$$
Z=\beta_{0}+\beta_{1} \cdot X_{1}+\beta_{2} \cdot X_{2}+\beta_{3} \cdot X_{3}+\beta_{4} \cdot X_{4}
$$

Where: $Z=\frac{1}{1+e^{-\left(\hat{a}_{0}+\sum_{i=1}^{n} \hat{a}_{i} \cdot X_{i}\right)}}$

and $\beta 0$ is a constant, $\beta \mathrm{i}$ are logistic regression coefficients and $\mathrm{Xi}$ are explanatory variables, these being:

$\mathrm{X}_{1=} R O A$

$\mathrm{X}_{2}=T L / T A$

$\mathrm{X}_{3}=$ CURRENT RATIO

$\mathrm{X}_{4}=O C F / T L$

We used the STATA statistical software package to carry out the estimates. The model was nested, which involves sequentially adding variables, in addition to comparing the incremental significance provided by each one, in order to test how the key variable increases the level of significance achieved by the model. Table 4 provides the descriptive statistics, presenting the group means and standard deviations of the four predictor variables.

The table reports data from the firms included in the initial sample, that is, 142 valid cases ( 71 failed and 71 non-failed firms). Both the size and signs of the group means are as expected.

Table 5 presents the test of significance of equality for the group covariance matrices. Significance close to zero validates the use of the linear discriminate function for estimation and classification purposes. The OCF/ TL variable has a significant influence on the dependent variable, as shown by the $p$ value; therefore, the inclusion of our variable enhances the reliability of the model.

\section{Empirical Results}

In this section we discuss the findings of the analysis. Table 6 reports the results obtained using our logistic regression model. We performed three estimations of the model, taking into account a different timeframe for each one, in order to ascertain the behaviour of the firms as failure approaches. Thus, we developed estimations for two, three and four years prior to failure.

The logistic regression provides evidence that ratio analysis is conclusive in predicting failure three years in advance (Model II). The signs of the coefficients confirm our expectations. The variables are statistically significant and the model is consistent.

The results show than three years prior, there is a positive relationship between OCF/TL and the possibility

Table 4 .

Descriptive statistics of explanatory variables

\begin{tabular}{cccccc}
\hline Variable & $\boldsymbol{N}$ & Mean & $\begin{array}{c}\text { Standard } \\
\text { Deviation }\end{array}$ & Min & Max \\
\hline ROA & 138 & 0 & 1 & -2.865 & 6.400 \\
TL/TA & 129 & 0 & 1 & -2.365 & 6.119 \\
CURRENT & 140 & 0 & 1 & -0.283 & 11.339 \\
RATIO & & & & & \\
OCF/TL & 113 & 0 & 1 & -2.955 & 6.069 \\
\hline
\end{tabular}

Note. Where $\mathrm{N}$ is the number of observations, ROA is the return on assets, TL/TA is total liabilities/total assets, LIQUIDITY is current assets/current liabilities and OCF/TL is the operating cash flow/total liabilities. 
Table 5.

Correlation matrix s

\begin{tabular}{|c|c|c|c|c|c|}
\hline & $Z$ & $R O A$ & $T L / T A$ & CURRENT RATIO & $O C F / T L$ \\
\hline$Z$ & 1.000 & & & & \\
\hline \multirow[t]{2}{*}{$R O A$} & $0.311^{*}$ & 1.000 & & & \\
\hline & $(0.000)$ & & & & \\
\hline \multirow[t]{2}{*}{$T L / T A$} & $-0.344^{*}$ & $-0.388^{*}$ & 1.000 & & \\
\hline & $(0.000)$ & $(0.000)$ & & & \\
\hline \multirow[t]{2}{*}{ CURRENT RATIO } & $0.165^{*}$ & $0.022^{*}$ & $-0.295^{*}$ & 1.000 & \\
\hline & $(0.050)$ & $(0.797)$ & $(0.000)$ & & \\
\hline \multirow[t]{2}{*}{$O C F / T L$} & $0.310^{*}$ & $0.180^{*}$ & $-0.332^{*}$ & $0.436^{*}$ & 1.000 \\
\hline & $(0.000)$ & $(0.055)$ & $(0.000)$ & $(0.000)$ & \\
\hline
\end{tabular}

Note. Table 5 presents Pearson correlations; p-values are given in parentheses. All variables are as defined in Table 3. The significance level is ${ }^{*} 10$ per cent.

Table 6.

\section{Regression results}

\begin{tabular}{|c|c|c|c|}
\hline \multirow{2}{*}{ Explanatory Variable } & Model I & Model II & Model III \\
\hline & $(n-4)$ & $(n-3)$ & $(n-2)$ \\
\hline \multirow[t]{2}{*}{$R O A$} & -0.241 & $0.606^{* *}$ & 0.752 \\
\hline & $(0.243)$ & $(0.331)$ & $(0.513)$ \\
\hline \multirow[t]{2}{*}{$T L / T A$} & $-0.613^{* *}$ & -0.489 & $-0.952^{* *}$ \\
\hline & $(0.265)$ & $(0.379)$ & $(0.450)$ \\
\hline \multirow[t]{2}{*}{ CURRENT RATIO } & 1.666 & $6.804^{* * *}$ & $5.470^{* * *}$ \\
\hline & -1.204 & -2.643 & -2.185 \\
\hline \multirow[t]{2}{*}{$O C F / T L$} & 0.051 & $1.183^{* * *}$ & $0.809^{*}$ \\
\hline & $(0.275)$ & $(0.494)$ & $(0.566)$ \\
\hline \multirow[t]{2}{*}{ _cons } & -0.168 & 0.649 & 0.221 \\
\hline & $(0.248)$ & $(0.445)$ & $(0.392)$ \\
\hline Number of obs. & 105 & 111 & 114 \\
\hline Pseudo- $R^{2}$ & $8.65 \%$ & $24.53 \%$ & $24.46 \%$ \\
\hline Prob $>c h i^{2}$ & 0.0149 & 0.0000 & 0.0000 \\
\hline
\end{tabular}

Note. Table 6 presents estimated coefficients, where the independent variables are as follows: $R O A$ is the return on assets, TL/TA is total liabilities/total assets, CURRENT RATIO is current assets/current liabilities and OCF/TL is the operating cash flow/total liabilities. Standard errors are reported in brackets. ${ }^{*}$ Statistical significance level at $10 \%$. ${ }^{*}$ Statistical significance level at $5 \%$. ${ }^{* *}$ Statistical significance level at $1 \%$.

Table 7.

Marginal effect: Model II

\begin{tabular}{cc}
\hline Notation & Marginal effect $(\boldsymbol{x} \mathbf{1 0 0})$ \\
\hline$R O A$ & 0.151 \\
TL/TA & -0.122 \\
CURRENT RATIO & 1.701 \\
OCF/TL & 0.295 \\
\hline
\end{tabular}

of the firm not having insolvency problems; in this case we do not reject our preliminary hypotheses. OCF/TL has the strongest influence over the level of financial health forecasted by the model; a one-point variation in OCF/TL implies a 1.18 point increase in the score. The variable is statistically significant at the $1 \%$ confidence level. Therefore, the variable that includes cash flow from operations explains $99 \%$ of the model.

A discrete change in profitability increases the score by 0.61 points, and we find a positive relationship with the dependent variable. This variable has a significant influence on the financial health of the firm, reaching statistical significance at 5\%. We find a negative link with levels of indebtedness, and if the variable increases by one point, the probability of financial health decreases by 0.49 points. Finally, we find a positive relationship between liquidity and the dependent variable, where a one point increase in liquidity yields an increase of 6.80 in the dependent variable, with a significance level of 5\%.

In summary, as expected, profitability, liquidity and ability to repay (measured as OCF/TL) have a positive and significant influence on the financial health of the firm, reaching statistical significance at $5 \%$ in the case of profitability, and $1 \%$ in the case of liquidity and ability to repay.

For two years (Model III) in advance, the model is significant but the results are not as consistent as they are for three years before failure. Particularly, the level of statistical significance achieved by the OCF/TL variable decreases from $99 \%$ when used three years prior to failure to $90 \%$ for two years before failure. In the case of four 
years (Model I), the regression results show that the model must be rejected.

The results obtained in the nested test conclude that our variable increases the significance of Model II by $2.13 \%$, a relevant percentage of the model's total significance. However, this increase is just $0.34 \%$ in Model I.

The marginal effects give us a more reliable idea of how much the probability of predicting business failure increases given a specific variation in the explanatory variables when we use logistic regression. The results are shown in Table 5. The marginal effect (in percentage terms) of the OCF/TL variable is equal to 0.3 (See Table 7). When this ratio increases by one unit, the probability that a firm will not have failure problems will increase by $0.3 \%$ when the other variables are controlled. In fact, the OCF/TL ratio appears to exert more influence on the probability of predicting business failure than others frequently used in previous studies, such us profitability and indebtedness. This is an expected outcome, given the results obtained in the regression model (Model II).

Moreover, we performed a test to measure the fit of the model, showing that $77.48 \%$ of the observations are correctly classified. The results indicate that the probability of correctly classifying the failure of a firm is $90.48 \%$ when the cut-off point is 0.5 . If we move the cut-off point to 0.57 , the value increases to $95.24 \%$.

As a result of all the above, the formula obtained in our model can be expressed as follows:

$$
Z=0.649+0.606 \cdot X_{1}-0.489 \cdot X_{2}+6.804 \cdot X_{3}+1.183 \cdot X_{4}
$$

Where:

$\mathrm{X}_{1=} R O A$

$\mathrm{X}_{2}=T L / T A$

$\mathrm{X}_{3}=$ CURRENT RATIO

$\mathrm{X}_{4}=O C F / T L$

If the result provided by the formula is above 0.57 this means that there is a high probability that the company is financially healthy, whereas if this result is below 0.57 , there is a high probability that the company has insolvency problems.

As the control sample for Model II, we used a set of 1,792 healthy firms in 2017 and 30 firms that initiated insolvency proceedings in 2013, 2014, 2017 and 2018. By doing so, we obtain results that verify the reliability of this model, its high degree of correct classifications $-100 \%$ in the case of failed firms - and the increase in significance provided by the OCF/TL variable.

\section{Conclusions}

This paper provides empirical evidence on the influence of variables based on cash flow statements in relation to business failure prediction. Following Mills and Yamamura (1990), who indicate that ratios based on cash flow statements offer a better measure of liquidity than those taken from the balance sheet and income statement, we included the variable operating cash flow/total liabilities among the predictors of business insolvency. Our study focuses on Spanish medium-sized firms, thus helping to fill a gap in the literature, because substantially more previously-published empirical studies have focused on failure prediction in large firms than on SMEs (Tascón et al., 2018).

The model confirms the results of previous studies regarding the significance of accounting information in business failure prediction, particularly the key role of liquidity in bankruptcy forecasting. Our findings show a model capable of predicting business failure three years in advance of that failure, with a high degree of consistency. OCF/TL is a conclusive ratio and useful in predicting failure, providing significance to the model and, interestingly, it is more relevant than others frequently used in previous studies, such as profitability and indebtedness. Additionally, our findings show that the ability to repay, measured using the OCF/TL variable, reaches its highest reliability in predicting failure three years in advance. That is, this ratio provides signs of failure further in advance than other ratios, thus allowing greater manoeuvrability to take corrective action.

The initial timeframe studied was subsequent to the global financial crisis in order to avoid its influence on our results. However, when the model is run for the control sample, which includes failures in years affected by the crisis, the results of the model are still consistent.

Model II offers a high degree of accurate classifications of failed firms, reaching $95.24 \%$ when the cut-off is set at 0.57 , so the most costly mistakes, which involve classifying firms as healthy when they actually had insolvency problems, are minimal.

The results are relevant because they provide evidence regarding the usefulness of the data obtained from cash flow statements to predict failure in medium-sized firms. Consequently, the analysis suggests the usefulness of taking into account information provided by cash flow 
statements when making decisions regarding lending to firms and also, from the viewpoint of medium-sized firms, in relation to the acceptable level of leverage to assume. We even suggest that using this information could be relevant for small businesses, for which the cash flow statement is not compulsory, and the findings of the paper may suppose an incentive to reveal it. The importance of OCF as a predictor of business failure implies paying greater attention to the cash flow statement, and as a consequence a bigger emphasis on cash management. On the other hand, the results of our study suggest that potential creditors should pay special attention to the information provided by OCF when they make decisions about financing companies.

\section{Notes}

i The authors do not explain the calculation of these values. As this research looks at small firms, which are not obliged to produce a cash flow statement, we deduce that the authors used the cash flow obtained from the income statement, adding depreciation and amortisation expenditure to net profit, in a similar way to the "generated resources before taxes/total liabilities" ratio, also provided by the SABI database.

ii The adjustments eliminate expenses and income that do not involve treasury movements, those that correspond to investment or financing flows and take into account changes in working capital. Finally, the charges/payments for interest and taxes on profit, which Spanish regulations include in the OCF, are presented directly.

iii TRCF is the most frequently used version of cash flow in financial studies. Unlike the version we use in this study, it is not standardized, so the profit figure that is taken as an initial point can change depending on the studies, and does not take into account working capital variations.

iv www.webconcursal.com consulted in May 2018.

\section{References}

Agarwal, V., \& Taffler, R. (2008). Comparing the performance of market-based and accounting-based bankruptcy prediction models. Journal of Banking and Finance, 32(8), 1541-1551. https://doi.org/10.1016/j. jbankfin.2007.07.014
Alaka, H. A., Oyedele, L. O., Owolabi, H. A., Kumar, V., Ajayi, S. O., Akinade, O. O., \& Bilal, M. (2018). Systematic review of bankruptcy prediction models: Towards a framework for tool selection. Expert Systems with Applications, 94, 164-184.

Altman, E. (1968). Financial ratios, discriminant analysis and the prediction of corporate bankruptcy. Journal of Finance, 23(4), 589-609.

Altman, E. (1981). Financial Handbook. (5th ed.). New York: John Wiley and Sons.

Altman, E., Haldeman, R.G., \& Narayanan, P., (1977). ZETATM analysis: A new model to identify bankruptcy risk of corporations. Journal of Banking and Finance, 1 (1), 29-54.

Altman, E. I., Iwanicz-Drozdowska, M., Laitinen, E. K., $\&$ Suvas, A. (2017). Financial distress prediction in an international context: A review and empirical analysis of Altman's Z凶Score model. Journal of International Financial Management \& Accounting, 28(2), 131-171. doi: $10.1111 /$ jifm. 12053

Amat, O. (1990) Predicción del éxito o fracaso de una empresa en base a variables cualitativas y cuantitativas (Tesis Doctoral). Universitat Autónoma de Barcelona, Barcelona, Espanha.

Amat, O. (2005). Claves del análisis de empresas. Revista de Contabilidad y Dirección, (2), 13-51. Retrieved from https://accid.org/wp-content/uploads/2018/09/ analisis_castellano_013-051.pdf

Amat, O., Manini, R., \& Renart, M. A. (2017). Credit concession through credit scoring: Analysis and application proposal. Intangible Capital, 13(1), 51-70. doi: 10.3926/ic.903

Aziz, A., \& Lawson, G. H. (1989). Cash flow reporting and financial distress models: Testing of hypotheses. Financial Management, 18(1) 55-63.

Bhandari, S. B., \& Iyer, R. (2013). Predicting business failure using cash flow statement based measures. Managerial Finance, 39(7), 667-676. 
Beaver, W. H. (1966). Financial ratios as predictors of failure. Journal of Accounting Research, 4(suppl. 3), 71-111.

Bell, T. B., Ribar, G. S., \& Verchio, J. (1990, Jan.). Neural nets versus logistic regression: A comparison of each model's ability to predict commercial bank failures. Proceedings of the University of Kansas Symposium on auditing problems, Lawrence, Kansas. Retrieved from: https://egrove.olemiss.edu/dl_proceedings/82/

Campillo, J. P., Serer, G. L. \& Ferrer, E. V. (2013). Validez de la información financiera en los procesos de insolvencia: Un estudio de la pequeña empresa española. Cuadernos de Economía y Dirección de la Empresa, 16(1), 29-40.

Casey, C. J., \& Bartczak, N. J. (1984). Cash Flow. It is not the bottom line. Harvard Business Review, 60-66.

Casey, C. J., \& Bartczak, N. J. (1985). Using operating cash flow data to predict financial distress: Some extensions. Journal of Accounting Research, 23(1), $384-401$

Davydenko, S. A. (2007). When do firms default? A study of the default boundary. AFA 2009 San Francisco Meetings Paper. Stanford, CA. Retrieved from: http:// ssrn. $\operatorname{com} /$ abstract $=672343$

Deakin, E. B. (1972). A discriminant analysis of predictors of business failure. Journal of Accounting Research 10 (1), 167-179.

DeFond, M. L., \& Hung, M. (2003). An empirical analysis of analysts' cash flow forecasts. Journal of Accounting and Economics, 35(1), 73-100.

Diéguez-Soto, J. (2009). Análisis crítico del estado de flujos de efectivo de las actividades de explotación del PGC2007 y su utilización en la evaluación de la solvencia empresarial. Revista de contabilidad y tributación: Comentarios, casos prácticos, (319), 209-244.

Edmister, R. (1972). An empirical test of financial ratio analysis for small business failure prediction. Journal of Financial and Quantitative Analysis, 7(2), 1.477-1.493.
Enguídanos, A. M. (2009). Los modelos de predicción del fracaso empresarial: Una aplicación empírica del logit. Revista Española de Financiación y Contabilidad, 24(78), 203-233.

García-Gallego, A \& Mures-Quintana, M.-J. (2013). La muestra de empresas en los modelos de predicción del fracaso: influencia en los resultados de clasificación. Revista de Métodos Cuantitativos para la Economía y la Empresa,15 (1), 133-150.

García-Marí, J. H., Sánchez-Vidal, J., \& TomasetiSolano, E. (2016). Fracaso empresarial y efectos contagio: Un análisis espacial para España. El trimestre económico, 83(330), 429-449.

Gazengel, A. \& Thomas, P. (1992). Les défaillances d'entreprises. École Superieure de Commerce de Paris. Les Cabiers de Recherche, 105, 47 p.

Gepp, A. \& Kumar, K. (2008). The role of survival analysis in financial distress prediction. International Research Journal of Finance and Economics, (16), 13-34.

Gilbert, L. R., Menon, K. \& Schwartx, K. B. (1990). Predicting bankruptcy for firms in financial distress. Journal of Business Finance \& Accounting, 17(1), 161-171.

Gombola, M. J. \& Ketz, J. E. (1983). A note on cash flow and classification patterns of financial ratios. The Accounting Review, 58(1), 105-114.

Gombola, M. J., Haskins, M. E., Jr., Ketz, E., \& Williams, D. D. (1987). Cash flow in bankruptcy prediction. Financial Management, 16(4), 55-65.

Graham, J. R., Harvey, C. R. \& Rajgopal, S. (2005). The economic implications of corporate financial reporting. Journal of Accounting and Economics, 40(13), 3-73.

Graveline, J. \& Kokalari, M. (2008). Credit risk. (Working Paper), The Research Foundation of CFA Institute, November.

Hill, N. T., Perry, S. E. \& Andes, S. (1996). Evaluating firms in financial distress: An event history analysis. Journal of Applied Business Research, 12(13), 60-71. 
Jardin, P. du. (2015). Bankruptcy prediction using terminal failure processes. European Journal of Operational Research, 242(1), 286-303.

Korol, T. (2013). Early warning models against bankruptcy risk for Central European and Latin American enterprises. Economic Modelling, 31, 22-30.

Laitinen, E. K. (1994). Traditional versus operating cash flow in failure prediction. Journal of Business Finance \& Accounting, 21(2), 195-217.

Lee, L. F. (2012). Incentives to inflate reported cash from operations using classification and timing. The Accounting Review, 87(1), 1-33

Lo, A. W. (1986). Logit versus discriminant analysis. Journal of Econometrics, 31(2),151-178.

Mari-Vidal, S., Marin-Sánchez, M. D. M., SeguíMas, E., \& Michael-Zamorano, M. (2014). Análisis cualitativo de los determinantes en la predicción del fracaso empresarial en cooperativas agroalimentarias. Información Técnica Económica Agraria. 110(3), 300320. doi:10.12706/itea.2014.019

Martin, D. (1977). Early warning of bank failure. Journal of Banking and Finance, 1(3), 249-276.

Mills, J. R., \& Yamamura, J. H. (1998). The power of cash flow ratios. Journal of Accountancy, 186 (4), 53-61.

Misas, M. R. (2008). Análisis del fracaso empresarial en Andalucía: Especial referencia a la edad de la empresa. Cuadernos de Ciencias Económicas y Empresariales, 54,35-56.

Ohlson, J. A. (1980). Financial ratios and the probabilistic prediction of bankruptcy. Journal of Accounting Research, 18(1), 109-131

Paradi, J. C., Asmild, M., \& Simak, P. C. (2004). Using DEA and worst practice DEA in credit risk evaluation. Journal of Productivity Analysis, 21(2), 153-165.

Previts, G., Bricker, R., Robinson, T., \& Young, S. J. (1994). A content analysis of sell-side financial analyst company reports. Accounting Horizons, 8(2), 55-70.
Rodriguéz, A. C., Molina, M. A., \& Pérez, A. L. G. (2003). La insolvencia empresarial: un análisis empírico para la pequeña y mediana empresa. Revista de Contabilidad, 6(12), 47-79.

Serrano- Cinca, C. (1996). Self organizing neural networks for financial diagnosis. Decision Support Systems, 17(3), 227-238.

Serer, G. L., Campillo, J. P., \& Feres, E. V. (2009). Time modelling of the accounting ratios for detection of management failure in Spanish small and medium size entreprises. Revista Española de Financiación y Contabilidad, 38(143), 423-448.

Sharma, D. (2001). The role of cash flow information in predicting corporate failure: The state of the literature. Managerial Finance, 27(4), 3-28.

Shin, K.-S., \& Lee, Y.-J. (2002). A genetic algorithm application in bankruptcy prediction modelling. Expert Systems with Applications, 23(3), 321-328.

Sinkey, J. F., Jr. (1975). A multivariate statistical analysis of the characteristics of problem bank. The Journal of Finance, 30(1), 21-36.

Somoza-López, A. \& Vallverdu-Calafell, J. (2009). Una comparación de la selección de los ratios contables en los modelos de predicción de la insolvencia empresarial. Economía Industrial, (373), 153-168.

Sun, J., Jia, M.-Y., \& Li, H. (2011). Adaboost ensemble for financial distress prediction: An empirical comparison with data from Chinese listed companies. Expert Systems with Applications, 38(8), 9305-9312.

Taffler, R., (1983). The assessment of company solvency and performance using a statistical model: A comparative UK based study. Accounting and Business Research, 13(52), 295-307.

Tascón, M. T., Castaño F. J., (2012).Variables y modelos para la identificación y predicción del fracaso empresarial: Revisión de la investigación empírica reciente. Revista de Contabilidad, 15(1), 7-58. 
Tascón, M. T, Castaño F. J., \& Castro, P. (2018). A new tool for failure analysis in small firms: frontiers of financial ratios based on percentile differences (PDFR). Spanish Journal of Finance and Accounting: Revista Española de Financiación y Contabilidad, 47(4), 433463. doi: 10.1080/02102412.2018.1468058
Zavgren, C. V. (1983). The prediction corporate failure: The state of the art. Journal of Accounting Literature, (2), 1-38.

Zmijewski, M. E. (1984). Methodological issues related to the estimation of financial distress prediction models. Journal of Accounting Research, (22), 59-82. 


\section{Authors:}

1. Natividad Rodríguez-Masero, PhD, Pablo de Olavide University, Seville, Spain.

E-mail:nrodmas@upo.es

\section{ORCID}

(1) 0000-0003-3395-2190

2. Jesús D. López-Manjón, PhD, Pablo de Olavide University, Seville, Spain.

E-mail: jdlopman@upo.es

ORCID

(1) 00000-0002-0075-3294

\section{Contribution of each author}

\begin{tabular}{lcc}
\hline \multicolumn{1}{c}{ Contribution } & $\begin{array}{c}\text { Natividad Rodríguez- } \\
\text { Masero }\end{array}$ & Jesús D. López-Manjón \\
\hline 1. Definition of research problem & $\sqrt{ }$ & $\sqrt{ }$ \\
2. Development of hypotheses or research questions (empirical studies) & $\sqrt{ }$ \\
3. Development of theoretical propositions (theoretical work) & $\sqrt{ }$ \\
4. Theoretical foundation/literature review & $\sqrt{ }$ \\
5. Definition of methodological procedures & $\sqrt{ }$ & $\sqrt{ }$ \\
6. Data collection & $\sqrt{ }$ \\
7. Statistical analysis & $\sqrt{ }$ & $\sqrt{ }$ \\
8. Analysis and interpretation of data & $\sqrt{ }$ \\
9. Critical revision of the manuscript & $\sqrt{ }$ \\
10. Manuscript writing & & $\sqrt{ }$ \\
11. Other (please specify which) & & $\sqrt{ }$ \\
\hline
\end{tabular}

